\title{
DIFICULDADES ORTOGRÁFICAS PRESENTES NAS PRODUÇÕES TEXTUAIS DE ALUNOS DO 5 ANO DO ENSINO FUNDAMENTAL I
}

\author{
Patrícia Regina de Souza ${ }^{1}$, Ana Luzia Videira Parisotto ${ }^{2}$ \\ Universidade Estadual Paulista - FCT/UNESP. ${ }^{1}$ Curso de Pedagogia, Presidente Prudente - SP. ${ }^{2}$ Departamento de \\ Educação, Presidente Prudente - SP. E-mail: patyysouza650@gmail.com \\ Órgão de fomento: FAPESP
}

\section{RESUMO}

Neste trabalho objetivamos demonstrar as dificuldades ortográficas apresentadas por alunos do 5 ㅇ ano do ensino fundamental $\mathrm{I}$, a fim de suscitar uma reflexão sobre o ensino de ortografia. 0 estudo está fundamentado na literatura referente à alfabetização, ensino de ortografia, variação linguística e produção textual. A investigação é de natureza quali/quantitativa por meio da qual descrevemos, categorizamos e indicamos a frequência dos erros ortográficos presentes nas produções textuais dos alunos. Os resultados apontam que os discentes apresentam muitas dificuldades com relação às regularidades e irregularidades ortográficas. Dessa forma, destacamos a importância de um ensino sistemático e reflexivo da ortografia para que possam refletir sobre suas dificuldades e tenham mais chance de êxito na apropriação do sistema ortográfico.

Palavras-chave: Ensino de ortografia, variação linguística,regularidades e irregularidades ortográficas, aquisição da escrita, produção textual.

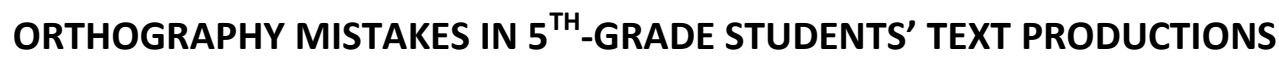

\begin{abstract}
The purpose of this study is to point out orthographic difficulties presented by $5^{\text {th }}$-grade students in order to prompt a debate about the teaching of orthography. The study is based on literature on literacy, the teaching of orthography, language variation, and text production. This research, of a qualitative/quantitative nature, describes, categorizes, and indicates the frequency of misspellings present in students' text productions. Results indicate that students have numerous problems in relation to orthographic regularities and irregularities. Thus, it emphasizes the importance of systematic and reflective teaching of orthography so as to have students think about their difficulties, thereby increasing their chance of effectively appropriating the orthographic system.

Keywords: Teaching of orthography; linguistic variation; spelling regularities and irregularities; writing acquisition; textual production.
\end{abstract}




\section{INTRODUÇÃO}

A capacidade de se comunicar e interagir por meio da língua escrita é considerada, na sociedade contemporânea, uma importante ferramenta para a aquisição de conhecimentos e condição básica para o sucesso escolar. Todavia, para aprender a escrever é preciso ter o domínio do sistema alfabético, e, além de tudo, é preciso aprender a ortografia. No entanto, devido à complexidade do nosso sistema de escrita "[...] a tarefa do aprendiz da ortografia é também complexa e exige apropriar-se de regras" (SANTOS, BARRERA, 2012, p. 258).

Devido às dificuldades em lidar com o sistema ortográfico, as pessoas, às vezes, veem a ortografia como uma imposição inútil e gostariam que escrevêssemos da forma como falamos, mas a ortografia é algo fundamental na escrita, já que se não fosse por ela teríamos dificuldades em entender a escrita que seria de acordo com as diferentes pronúncias presentes em cada região do país. Nesse sentido, a ortografia tem, então, a função de cristalizar a escrita facilitando a comunicação, todavia isso não significa que não tenhamos liberdade de pronunciarmos as palavras de acordo com as variações possíveis e previstas pelo nosso sistema linguístico. De acordo com Morais (2009), há palavras que podem ser pronunciadas de várias formas, como por exemplo: tio (tchiô, tiu etc.).

Entretanto, devido à complexidade do sistema ortográfico, as crianças passam por grandes dificuldades ao lidar com as complicadas relações entre sons e letras (LEMLE, 1999). Essas dificuldades se intensificam na medida em que os professores têm ensinado a ortografia por meio de tarefas mecânicas e repetitivas, como cópias e ditados. Essas atividades podem não contribuir para que os alunos reflitam sobre o sistema ortográfico. Dessa forma, as tarefas de recitação/memorização de regras ortográficas não têm feito com que os alunos incorporem a regra de uma forma consciente (MORAIS, 2009).

Morais (2009), assim como muitos autores (COLELLO, 2007; CAGLIARI e MASINI-CAGLIARI, 1999; CAGLIARI, 2009), enfatiza que a normas ortográficas só podem ser apropriadas pelos alunos por meio de um ensino sistemático e reflexivo, pois, para tal autor, é necessário que, de fato, se invista na ortografia. O que não tem acontecido, pois a ortografia tem sido vista como um mero objeto de avaliação na sala de aula, por meio da qual se verifica se o aluno aprendeu a escrever certo, sem que haja uma reflexão sobre os erros.

Sendo assim, em muitos casos, o ensino de ortografia tem se restringido à verificação da norma ortográfica, por meio dos ditados: se o aluno acerta é sinônimo de que está bom, caso contrário é preciso que copie a palavra correta, como se isso fizesse com que o aluno aprendesse. O autor critica de forma enfática essas atividades de cópia, conforme as crianças avançam na 
escolaridade, pois, segundo ele, os alunos apenas cumprem o "fardo" de copiar: alguns copiam rapidamente sem refletir sobre as palavras, outros que fazem a atividade mais devagar também fazem-na sem interesse e isso não contribui para que os alunos reflitam sobre a escrita das palavras de modo a organizar seus conhecimentos ortográficos.

Cagliari (2002) aponta que, para sanar as dúvidas ortográficas dos alunos e para que eles tenham êxito na aquisição do sistema ortográfico, é imprescindível que a ortografia não seja colocada como um aspecto secundário dentro da sala de aula, pois em decorrência disso é que os alunos têm tido muitas dificuldades no que diz respeito à escrita ortográfica.

Neste sentido, a questão norteadora que se colocou para a pesquisa foi: Quais são os principais erros ortográficos presentes nos textos produzidos por alunos do quinto ano do Ensino Fundamental I, de uma escola pública do município de Presidente Prudente?.

O objetivo geral da nossa investigação foi propiciar uma reflexão sobre o ensino da ortografia, por meio da análise dos erros ortográficos produzidos por alunos do 5 ano do Ensino Fundamental. Nessa perspectiva, tivemos como objetivos específicos: Analisar os erros ortográficos produzidos por alunos do 5o ano do Ensino Fundamental, à luz das regularidades e irregularidades apresentadas por Morais (2009); Categorizar os erros e observar a sua frequência; apresentar os dados analisados aos professores da unidade escolar a fim de suscitar uma reflexão sobre o ensino da ortografia.

\section{METODOLOGIA}

A respeito das abordagens de pesquisa, Laville e Dione (1999) acreditam que, os conflitos entre as abordagens qualitativas e quantitativas são inúteis, pois para os autores:

A partir do momento em que a pesquisa centra-se em um problema específico, é em virtude desse problema específico que o pesquisador escolherá o procedimento mais apto, segundo ele, para chegar à compreensão visada. Poderá ser um procedimento quantitativo, qualitativo, ou uma mistura de ambos. O essencial permanecerá: que a escolha da abordagem esteja a serviço do objeto de pesquisa, e não o contrário, com o objetivo de daí tirar, o melhor possível, os saberes desejados. (LAVILLE, DIONE, 1999, p. 43, grifo nosso).

Assim como tais autores, Gamboa (1995) também acredita que, superando falsos dualismos, podemos permitir a existência de vários enfoques que se definem num continuum. Nesse sentido, a metodologia desta investigação pautou-se na abordagem quali/quantitativa de pesquisa, por meio da qual descrevemos, categorizamos e indicamos a frequência dos erros ortográficos presentes nas produções textuais de alunos do ensino fundamental I. 
O corpus da pesquisa foi composto por produções textuais de todas as turmas de quinto ano de uma escola pública, situada no município de Presidente Prudente/SP. No entanto, neste trabalho, apresentamos um recorte da pesquisa, pois focalizamos apenas as dificuldades ortográficas presentes nas produções textuais de uma sala de quinto ano do ensino fundamental, totalizando dez textos que versavam sobre a reescrita do conto "Os músicos de Bremen". As dez produções textuais foram analisadas à luz da classificação estabelecida por Morais (2009) sobre as regularidades e irregularidades presentes no nosso sistema ortográfico.

\section{RESULTADOS}

Nossa pesquisa está em andamento, pois, de acordo com os objetivos previstos, analisaremos um total de trinta produções, observando os principais erros ortográficos, categorizando-os e indicando as frequências.

Em uma análise inicial dos dados relativos às dez produções textuais, pudemos observar que os alunos apresentam dificuldades ortográficas com relação à classificação estabelecida por Morais (2009). Percebemos que a maior incidência dos erros cometidos pelos alunos se refere às regularidades contextuais e, apesar de estarem no 50 ano do ensino fundamental, alguns ainda cometem falhas quanto às regularidades diretas que se caracterizam pelas trocas entre consoantes surdas e sonoras. Estas trocas são de ordem primária e, de acordo com Lemle (1999), deveriam ser sanadas no início da alfabetização.

A seguir, apresentamos, nos quadros 1 e 2 , os erros observados nas produções textuais, de acordo com a classificação estabelecida por Morais (2009) e no quadro 3, demonstramos a quantidade de ocorrências em cada uma das classificações.

Quadro 1. Dificuldades regulares do sistema ortográfico

\begin{tabular}{|c|c|}
\hline Regulares diretas & $\begin{array}{l}\text { Regulares morfológico } \\
\text { Gramaticais }\end{array}$ \\
\hline $\begin{array}{l}\text { Trumbete- (trompete)- } \\
\text { corento- (correndo)- } \\
\text { Tombeti- (trompete)- }\end{array}$ & $\begin{array}{l}\text { Montarão- (montaram)-Derão- } \\
\text { (deram)- } \\
\text { Forma- (formar) } \\
\text { Acharan- (acharam)- } \\
\text { Foran- (foram })^{-} \\
\text {Encontra- (encontram)- } \\
\text { esto- (estou)- } \\
\text { Tornaran- (tornaram)- } \\
\text { começaran (começaram)-Deixo- } \\
\text { (deixou)- } \\
\text { faze- (fazer)- }\end{array}$ \\
\hline
\end{tabular}




\begin{tabular}{|c|c|}
\hline & $\begin{array}{l}\text { Come- (comer)- } \\
\text { estavan- (estavam)- } \\
\text { Afugentaran- (afugentaram }) \text { - } \\
\text { Encontrarão- (encontraram } \text { - } \\
\text { emtro- (entrou)- } \\
\text { forma- (formar)- }\end{array}$ \\
\hline
\end{tabular}

Quadro 2. Dificuldades regulares e irregulares do sistema ortográfico

\begin{tabular}{|c|c|}
\hline Regulares contextuais & Irregulares \\
\hline 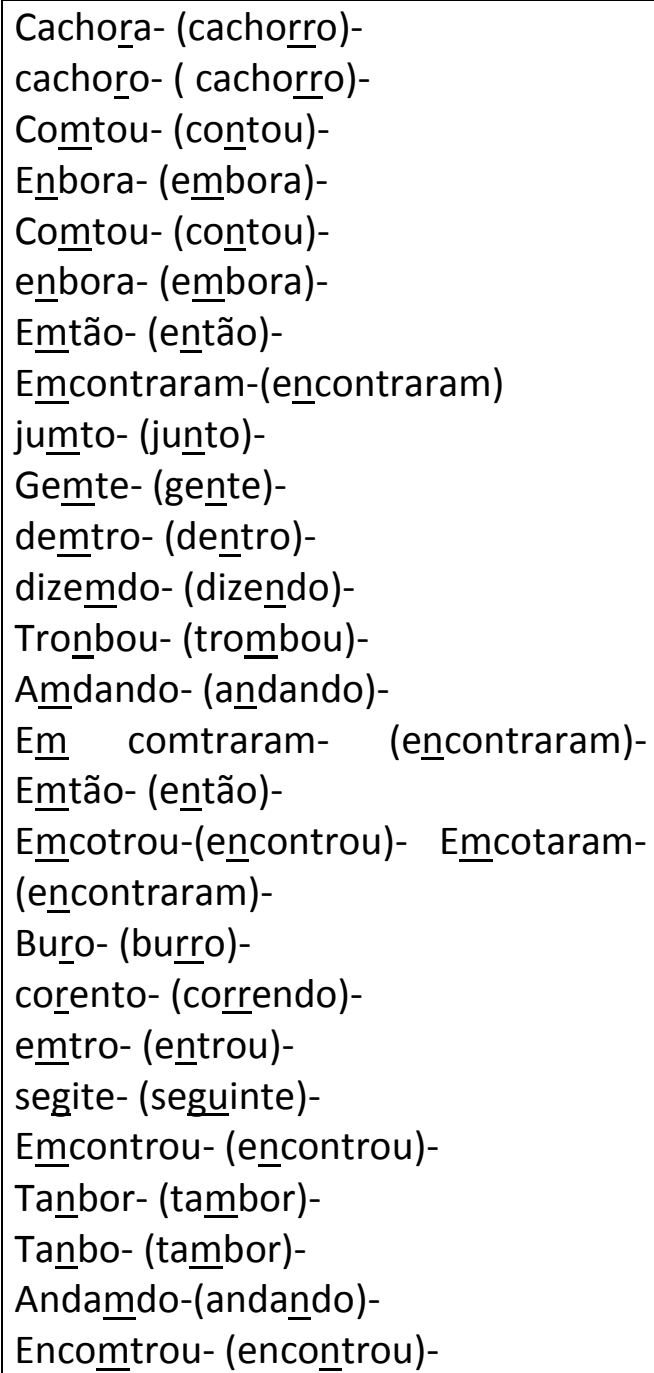 & 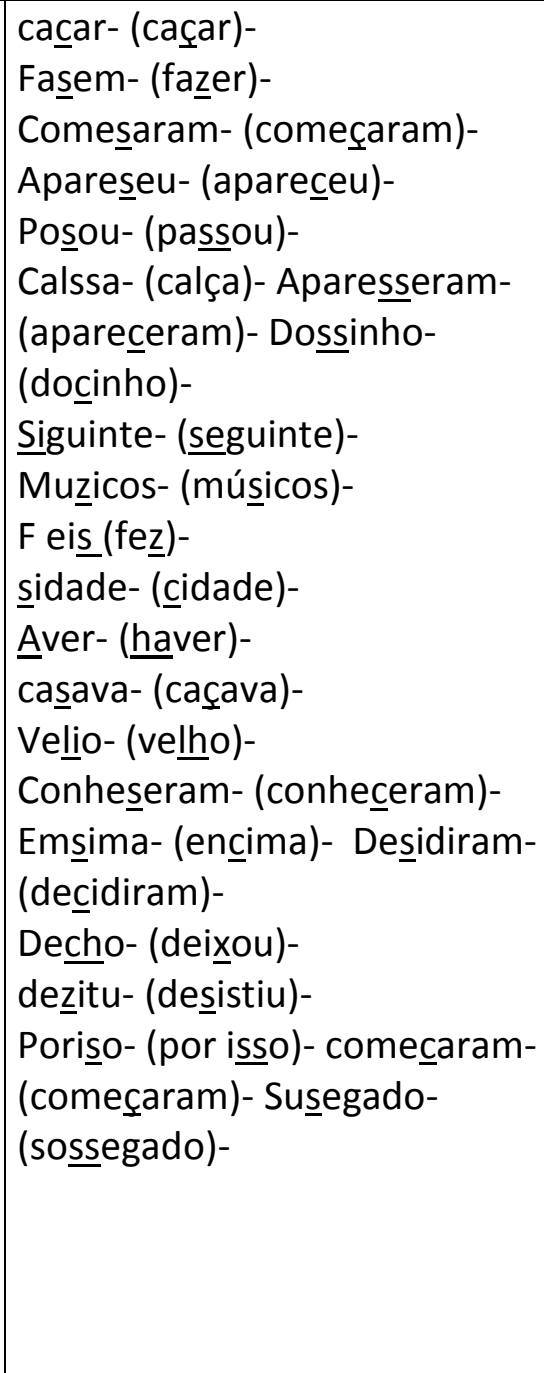 \\
\hline
\end{tabular}

Quadro 3. Número de ocorrências das dificuldades apresentadas pelos alunos em dez produções textuais

\begin{tabular}{|l|l|}
\hline Regulares diretas & 3 erros \\
\hline Regulares contextuais & 27 erros \\
\hline Regulares morfológico gramaticais & 18 erros \\
\hline Irregulares & 23 erros \\
\hline
\end{tabular}




\section{DISCUSSÃO}

Com relação à ortografia, é possível perceber que a maior dificuldade presente nos textos dos alunos diz respeito às regularidades contextuais, ou seja, aquelas em que o contexto interno da palavra é que define a letra (ou dígrafo) a ser usada. A disputa entre " $R$ " e "RR" é um bom exemplo. Dessa forma, nossos resultados parciais demonstram que tal ensino parece não ser objeto de reflexão nas aulas de Língua Portuguesa, pois, conforme aponta Morais (2009), para esse tipo de dificuldade ortográfica há regras subjacentes que devem ser explicitadas.

Outra dificuldade que aparece de forma acentuada nas dez produções textuais analisadas diz respeito às irregularidades do sistema ortográfico. Morais (2009) aponta que, as dificuldades relacionadas às arbitrariedades do sistema linguístico só serão entendidas se o aluno tiver imagens fotográficas de palavras que apresentem irregularidades ortográficas. O contato com materiais impressos, para o autor, faz-se necessário para a memorização de tais grafias.

Levando em conta o que o autor apresenta, parece-nos que o contato com materiais impressos de qualidade que possibilite a reflexão sobre as dificuldades com relação às arbitrariedades do sistema ortográfico não tem sido mediado pelo professor, pois há muitas ocorrências de erros relacionados a palavras de uso frequente, por exemplo, sidade/cidade.

Alguns alunos ainda apresentam erros de natureza primária, como é o caso das regularidades diretas, ou seja, as trocas entre consoantes surdas e sonoras. Lemle (1999) afirma que essas dificuldades, por serem de ordem primária, deveriam ser sanadas no início da alfabetização. Com relação às regularidades morfológico-gramaticais, as produções textuais analisadas também apresentam um grande número dessas ocorrências, nesse sentido, Lemle (1999) sugere que o professor poderia realizar um trabalho com os afixos. Segundo a autora, isso pode contribuir para que o aluno tenha mais segurança ao escrever.

\section{CONCLUSÃO}

Diante do exposto, observamos que, mesmo no 5o ano do ensino fundamental, a ortografia se apresenta como uma grande dificuldade, de acordo com o corpus analisado para este artigo e isso pode ser decorrente do fato de a ortografia ter sido colocada como um aspecto secundário nas aulas de Língua Portuguesa. Dessa forma, ressaltamos a importância de um ensino sistemático e reflexivo de ortografia a fim de que os alunos possam refletir sobre ela, o que fará com que tenham mais chance de êxito na apropriação do sistema ortográfico.

Além de tudo o que já foi mencionado anteriormente, acreditamos ser fundamental que o professor tenha um conhecimento profundo do sistema ortográfico de modo a poder entender a 
natureza dos erros de seus alunos. Assim, o professor compreenderá que os erros são de naturezas distintas e, portanto, caberá a ele estabelecer diferentes estratégias de ensinoaprendizagem para que os alunos se apropriem das regularidades e irregularidades presentes no nosso sistema ortográfico. Enfatizamos ainda que é importante o estabelecimento de metas para o ensino de ortografia, observando que a reflexão e o acesso a materiais escritos de qualidade se configuram como essenciais para que os alunos se apropriem do sistema ortográfico.

\section{REFERÊNCIAS}

CAGLIARI, L. C. Alfabetização \& Linguística. São Paulo: Scipione, 2009. . Alfabetização e ortografia. Educar, Curitiba: UFPR, n.20, p. 43-58, 2002.

CAGLIARI, L. C.; MASSINI-CAGLIARI, G. Diante das letras: a escrita na alfabetização. Campinas/SP: Mercado de Letras, 1999.

COLELLO, S. M. G. A escola que (não) ensina a escrever. São Paulo: Paz e Terra, 2007.

GAMBOA, S. S. Quantidade-Qualidade: para além do dualismo técnico e de uma dicotomia epistemológica. In: SANTOS FILHO, J. C.; (org.). Pesquisa Educacional: quantidadequalidade. São Paulo: Cortez, 1995.

LEMLE, M. Guia teórico do alfabetizador. São Paulo: Ática, 1999.

LAVILLE, C.; DIONNE, J. A construção do saber: manual de metodologia da pesquisa em ciências humanas. Porto Alegre: UFMG, 1999.

MORAIS, A. G. Ortografia: ensinar e aprender. 5. ed. São Paulo: Ática, 2009.

SANTOS, M. J.; BARRERA, S. D. Relação entre conhecimento explícito da ortografia e desempenho ortográfico. Revista Semestral da Associação Brasileira de Psicologia Escolar e Educacional, SP, v. 16, n. 2, p. 257-263, jul./dez. 2012. http://dx.doi.org/10.1590/S1413-85572012000200008 